\title{
O efeito do relevo nas chuvas na porção central do Estado de São Paulo em anos padrão extremos
}

\section{The effect of relief on rain in the central area of the State of São Paulo in extreme standard-years}

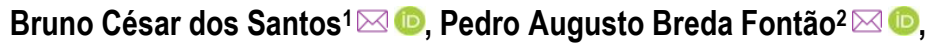 \\ Paulo Henrique de Souza*3凶(i)
}

\author{
${ }^{1}$ Escola de Engenharia de São Carlos, Universidade de São Paulo, São Carlos, \\ São Paulo, Brasil \\ 2Departamento de Geografia, Setor de Ciências da Terra, Universidade Federal do Paraná, \\ Curitiba, Paraná, Brasil \\ 3/nstituto de Ciências da Natureza, Universidade Federal de Alfenas, Afenas, \\ Minas Gerais, Brasil \\ E-mail: bruno-unifal@hotmail.com (BCS); pedrofontao@yahoo.com.br (PABF) \\ E-mail para correspondência: phsouza31@hotmail.com
}

Recebido (Received): 28/07/2020 Aceito (Accepted): 10/09/2020

Resumo: A precipitação é um elemento particularmente importante e variável no tempo e espaço, cuja ocorrência de eventos extremos tem potencial de ocasionar impactos significativos à população. Nessa perspectiva, a orografia é um fator que pode contribuir nesse processo desencadeado pela atmosfera, apresentando influências espaciais por meio das particularidades regionais de cada superfície topográfica e geomorfológica. Em vista disso, o presente estudo optou por investigar uma região que envolve 16 municípios localizados na porção central do Estado de São Paulo, inseridos numa área de transição geomorfológica, de relevância ecológica e palco de sucessivas ocorrências de eventos extremos de chuva. Nessa área de estudo, foram empreendidos esforços para definir anos-padrão representativos da dinâmica atmosférica habitual e excepcional da precipitação, realizou-se uma análise espacial das chuvas e selecionouse os dois anos mais representativos do padrão extremo chuvoso e seco (1983 e 2014, respectivamente) para uma análise detalhada do ritmo climático, buscando avaliar a participação e repercussão do relevo na distribuição das chuvas na região observada. Dessa maneira, verificou-se que o relevo apresentou uma significativa influência nas precipitações, com destaque para chuvas mais intensas em morfoestruturas de serras e cuestas existentes na região, fator que possivelmente continuará influindo na distribuição e intensidade das chuvas sobre a área estudada.

Palavras-chave: Precipitação; Orografia; Análise Rítmica; Interpolação; Climatologia Geográfica.

Abstract: Precipitation is a particularly important and variable element in time and space, whose occurrence of extreme events has the potential to cause significant impacts to the population. In this perspective, orography is a factor that can contribute to this process triggered by the atmosphere, presenting spatial influences through the regional particularities of each topographic and geomorphological surface. In view of this, the present study chose to investigate a region that involves 16 municipalities located in the central area of the State of São Paulo, inserted in an area of geomorphological transition, of ecological relevance and local importance for successive occurrences of extreme rain events. In this study area, efforts were made to define standard-years representative of the usual and exceptional atmospheric dynamics of precipitation, a spatial analysis of the rains was carried out and the two most representative years of the extreme rainy and dry pattern were selected (1983 and 2014 , respectively) for a detailed analysis of the climatic rhythm, seeking to evaluate the participation and repercussion of the relief in the distribution of rainfall in the region. Thus, it was found that the relief had a significant influence on rainfall, with emphasis on more intense rainfall in morphostructures of mountains and cuestas existing in the region, a factor that possibly will continue to influence the distribution and intensity of rainfall over the studied area.

Keywords: Precipitation; Orography; Rhythmic Analysis; Interpolation; Geographic Climatology. 


\section{Introdução}

A variabilidade das chuvas tem sido um tema constante e cada vez mais investigado nas pesquisas científicas, tendo em vista sua importância em escala regional e local, na medida em que as oscilações pluviométricas impactam nas mais diversas regiões do planeta. Nesse sentido, embora a atmosfera apresente condições habituais de tipos de tempo na maior parte do tempo, os eventos extremos têm o potencial de ocasionar situações para as quais a população de uma determinada área não se encontra preparada, como é o caso de chuvas intensas (GENOVEZ; ZUFFO, 2000; SANCHES et al., 2018), enchentes e inundações (ABREU et al., 2017), episódios de seca (SETH et al., 2015), dentre outras conjunturas impactantes. Por conseguinte, circunstâncias climáticas excepcionais passam a ser um objeto de atenção na gestão de riscos e ocorrem com maior frequência em anos destoantes do padrão habitual esperado, levando em conta o contexto das oscilações climáticas (EASTERLING et al., 2000).

Nesse entendimento, diversos estudos recentes têm apontado para tendências de alteração na distribuição espacial e temporal das chuvas, com uma possível intensificação dos eventos extremos, a exemplo de Donat et al. (2016), Marvel et al. (2017), Pfahl et al. (2017), entre outros. No entanto, sem embargo das atuais tendências e/ou projeções elaboradas pela modelagem climática, que acabam por valorizar ainda mais a importância de investigar este tema, ressalta-se que a própria ocorrência desses episódios ou períodos excepcionais (secos e chuvosos) já é algo bastante marcante na atualidade, e um dos escopos de investigação da Climatologia elaborada por geógrafos. É nessa perspectiva que Monteiro $(1971 ; 1973 ; 1991 ; 2015)$ propôs o conceito de anos-padrão, como forma de separar e categorizar anos (ou períodos) que representem comportamentos e características semelhantes quanto a uma determinada variável, e assim eleger momentos representativos para avançar na pesquisa utilizando técnicas dinâmicas como, por exemplo, a Análise Rítmica, procedimento tradicional e amplamente divulgado pela Escola Brasileira de Climatologia Geográfica (MONTEIRO, 2015; NEVES et al., 2017).

Diante disso, entende-se que adotar uma perspectiva espacial e geográfica nas análises climáticas apresenta relevância por contribuir com o entendimento dos fenômenos e dos processos desencadeados pela atmosfera, recobrando, por conseguinte, atenção às particularidades regionais de cada superfície, bem como aos aspectos topográficos e geomorfológicos que podem influenciar a distribuição de tais eventos no espaço geográfico, a exemplo das considerações apontadas por Roe (2005), Ebtehaj e Foufoula-Georgiou (2010) e Houze (2012). À vista disso, o presente estudo empreendeu esforços para entender a intensidade e a frequência das chuvas anuais (habituais e excepcionais), a dinâmica climática em dois anos-padrão distintos e a influência orográfica nesses episódios adotando como área de estudo a porção central do estado de São Paulo, definindo, para tanto, uma área de $9.151,7 \mathrm{~km}^{2}$ que integra um total de 16 municípios paulistas, com destaque para as duas maiores cidades em termos populacionais: São Carlos/SP e Rio Claro/SP.

A escolha da superfície de investigação desse ensaio não foi arbitrária, mas justifica-se pela região estar inserida em uma porção representativa de Área de Proteção Ambiental (APA-Corumbataí) de importância ecológica, situar-se numa área de transição geomorfológica com relativa influência das depressões, serras e cuestas na circulação atmosférica regional e por ser palco de sucessivas ocorrências de eventos extremos como chuvas intensas e episódios de seca retratados, por exemplo, nos estudos de Moruzzi e Oliveira (2009), Sanches et al. (2018), Santos et al. (2017), Maia et al. (2019), Gonçalves e Manzione (2019), Pereira et al. (2019), dentre outros. Tendo em vista a forte influência das águas provenientes da chuva na região, o objetivo desse estudo foi definir dois anos-padrão representativos da dinâmica atmosférica excepcional (seco e chuvoso), para, em conjunto com a análise do ritmo pluvial e dos sistemas atmosféricos atuantes nos anos selecionados, avaliar a participação do relevo na distribuição espacial das chuvas na região observada.

\section{Materiais e métodos}

\subsection{Caracterização da área de estudo}

A área investigada encontra-se localizada no centro-leste do estado de São Paulo, região Sudeste do Brasil, e compreende um total de 16 municípios paulistas: Analândia, Brotas, Charqueada, Corumbataí, Descalvado, Dois Córregos, Dourado, Ibaté, Ipeúna, Itirapina, Ribeirão Bonito, Rio Claro, Santa Maria da Serra, São Carlos, São Pedro e Torrinha (Figura 1). Tais municípios apresentam, segundo a classificação de Monteiro (1973), climas regionais tropicais alternadamente secos e úmidos com predomínio do tipo A2/Vb (Serra de São Carlos). Além disso, destacam-se por abranger em seu espaço, mesmo que parcialmente, a APA do Corumbataí, unidade estabelecida para proteger elementos naturais de importância ecológica ou paisagista e também é conhecida pelas suas atividades ecoturísticas, ostentando inúmeros atrativos naturais como a presença do relevo de cuestas basálticas, consideradas de grande fragilidade ambiental, além de apresentar áreas ocupadas por vegetação remanescente a serem preservadas (CORVALÁN; GARCIA, 2011). 


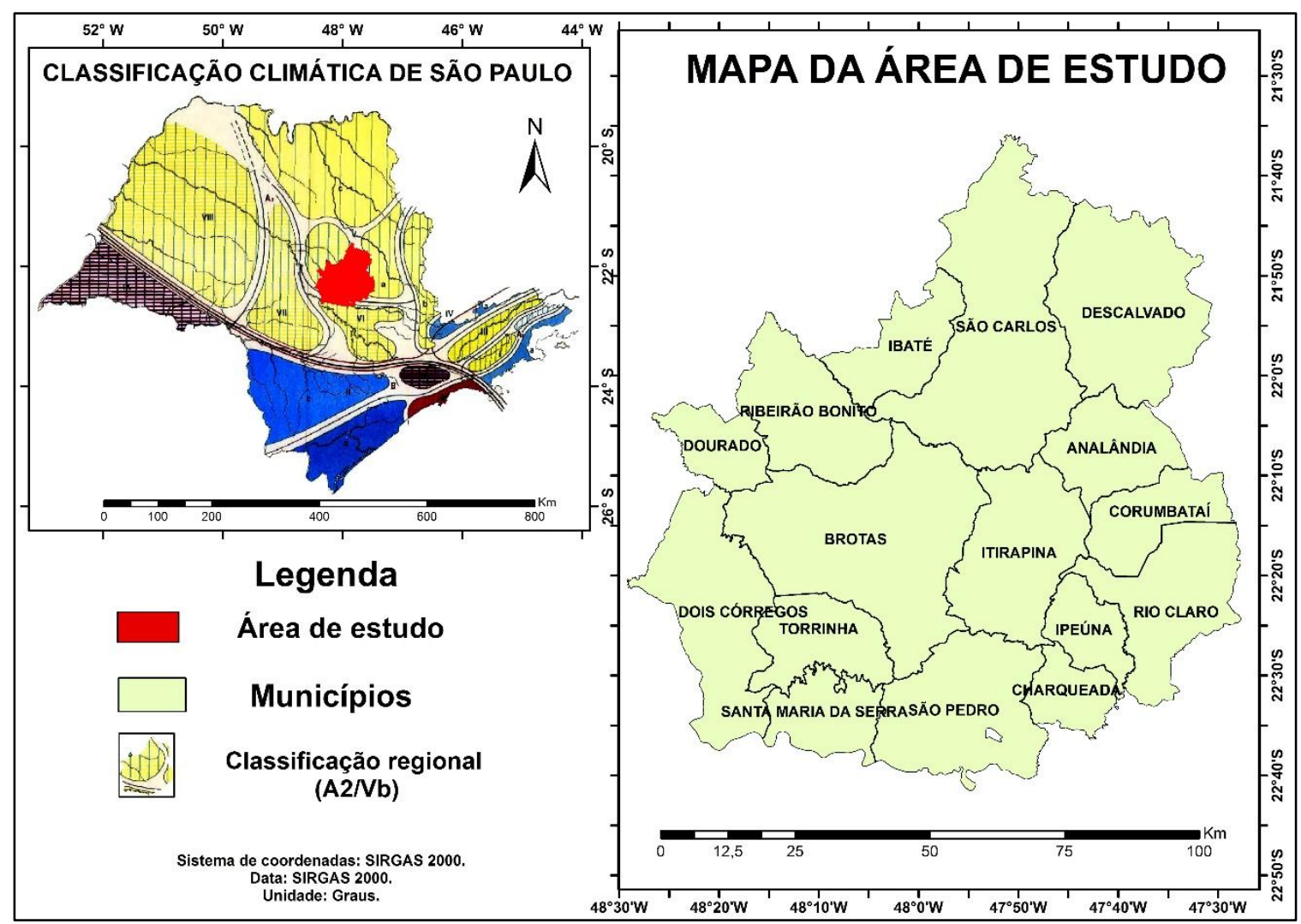

Figura 1: Mapa da localização da área de estudo.

Os aspectos geomorfológicos da região encontram-se divididos basicamente em duas morfoestruturas: à noroeste o Planalto Ocidental Paulista, formado numa grande zona de relevo suave compostas por colinas, morros baixos e serras com altitude média de 900 metros, e, à sudeste a Depressão Periférica Paulista, apresentando um relevo predominantemente colinoso e suave, além de morros e serras isoladas com altimetria média de 600 metros (ROSS e MOROZ, 1996; PINHEIRO e QUEIROZ NETO, 2014). À vista disso, a Figura 2 localiza a área de estudo e ilustra em seu interior a elevação e a declividade do terreno, evidenciando o relevo e as estruturas do local.

Ao norte da área selecionada no Planalto Ocidental Paulista destacam-se as serras de Santana, do Cuscuzeiro, de Atalaia e de São Carlos, entre os municípios de São Carlos, Itirapina, Analândia e Descalvado. Trata-se de morfoestruturas que constituem um extenso testemunho do recuo da chamada cuesta interior, com altitudes aproximadamente entre 800 a 1000 metros e com declividade acentuada de mais de 47\%, integrando o interflúvio correspondente ao divisor de águas dos rios da região (AGUILAR; CUNHA, 2015; PENTEADO, 1976). Mais ao sul da área de estudo, entre os municípios de Itirapina, Brotas, São Pedro e Torrinha, encontra-se a serra de Itaqueri, separando as duas grandes unidades geomorfológicas por um "paredão" íngreme de centenas de metros de elevação com declividade superior a $47 \%$ e alcançando aproximadamente 1100 metros de altitude no seu topo máximo. As serras também possuem uma orientação de leste-oeste, com suas escarpas (front) voltadas para o sul, leste e norte.

Segundo Tavares et al (1985) nessa região, em termos climáticos, há um contraste entre os fronts norte e sul da serra, devido a variação da insolação anual recebida em cada uma delas, sendo a escarpa sul mais fria e úmida do que a norte. Esta diferença também ocorre por conta da existência da mata natural na área, que contribui através da evapotranspiração e na configuração da estrutura atmosférica adjacente através da circulação do ar. Além da vegetação proteger o solo das escarpas da ação direta da chuva, dificulta e evita condições de inversão térmica prejudicais no desenvolvimento das culturas agrícolas, principalmente em períodos mais secos. Dessa forma, toda a conjuntura das serras situadas ao norte e ao sul da área tem um papel fundamental em colaborar com a dinâmica da circulação regional, principalmente, quando está sob a influência dos diferentes tipos de tempos que possam contribuir na formação ou intensificação das chuvas orográficas durante as sazonalidades do ano (SANTOS et al., 2018). 


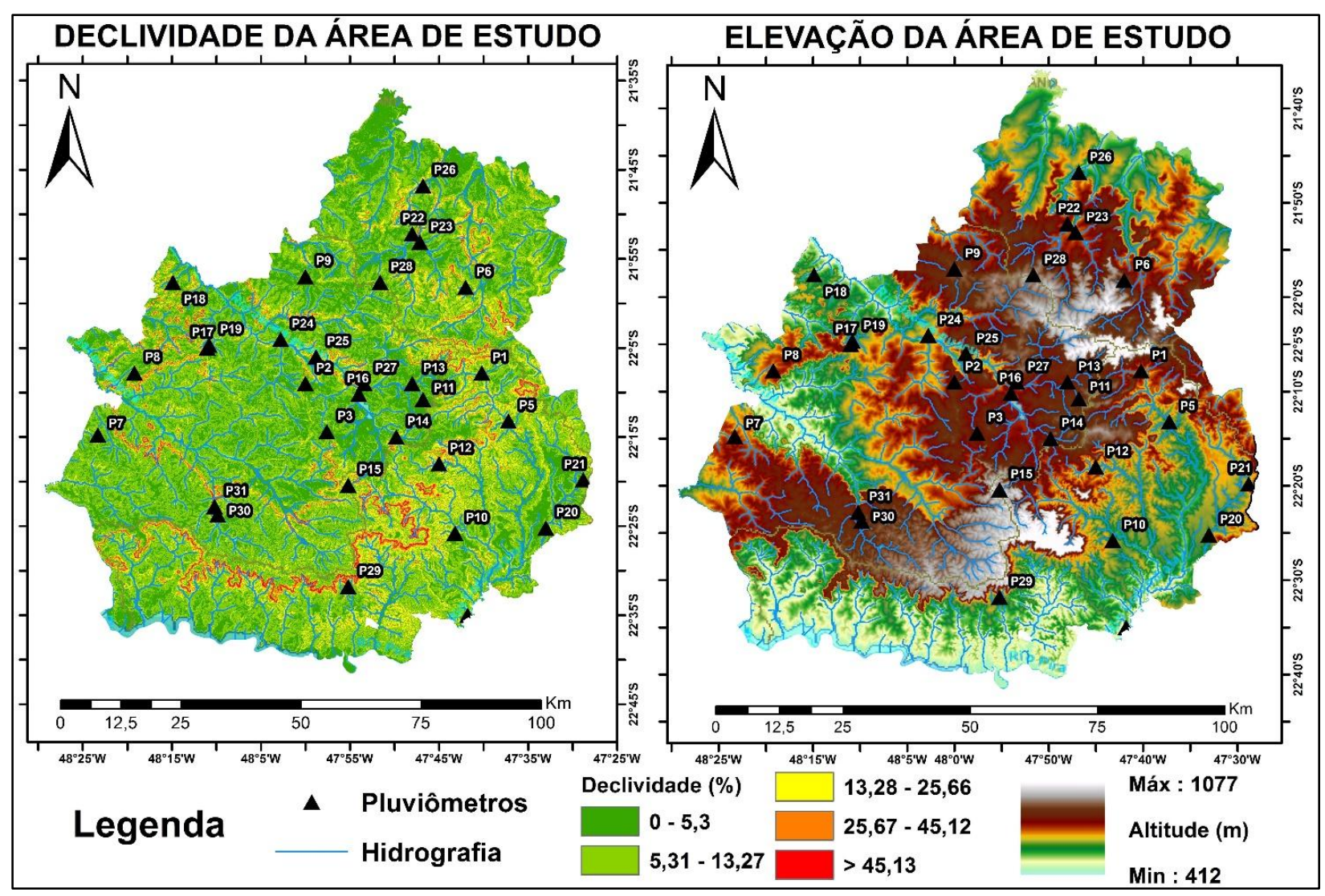

Figura 2: Declividade e Elevação da área de estudo.

Além disso, a região apresenta um padrão climático que, segundo Monteiro (1973), consiste em climas controlados pela ação das massas de ar somadas às constantes passagens e atuações da Frente Polar Atlântica, resultando num clima tropical alternadamente seco e úmido ao longo das estações do ano (verão chuvoso e inverno seco). O autor também relata que a faixa da borda do Planalto Ocidental Paulista, onde se encontra o relevo de cuestas, apresenta trechos mais elevados e, consequentemente, denotam um ligeiro aumento na quantidade de chuvas por efeito orográfico verificado durante o inverno. Tal fator constitui um importante aspecto de variação sazonal das precipitações segundo o caráter da circulação atmosférica regional e as influências do relevo.

\subsection{Seleção e tratamento dos dados pluviométricos}

A pesquisa selecionou e utilizou 31 postos pluviométricos inseridos no interior da área de estudo, todos contendo dados diários de chuva numa série histórica de 38 anos (1979-2017) e disponíveis através da plataforma online Hidroweb, da Agência Nacional de Águas (ANA), e no website do Centro Integrado de Informações Agrometeorológicas (CIIAGRO), vinculado à Secretaria de Agricultura e Abastecimento do estado de São Paulo. A Figura 2 e as cartas produzidas neste artigo apresentam a distribuição geográfica dos postos pluviométricos que foram utilizados.

Após adquirir os dados, foi realizada uma compilação das informações obtidas e um tratamento quantitativo dos dados diários de precipitação, organizando tudo na forma de tabelas e gráficos com o uso do software Microsoft Excel 2016 nas escalas temporais anual, mensal, diária e episódica, de maneira a otimizar a análise regional do estudo. Para tanto foi considerada uma hierarquia dimensional ou ordem de grandeza, espacial (extensão) e temporal (duração), relacionadas com o padrão atmosférico, uma vez que o clima se manifesta em todos os locais do Planeta (RIBEIRO, 1993; BARRY; CHORLEY, 2013).

A etapa seguinte ocupou-se com o processo de preenchimento mensal/anual das lacunas existentes nos dados dos postos que apresentaram falhas, para isto, foi utilizado o método da ponderação regional (BERTONI e TUCCI, 2009). Este método é capaz de estimar o valor de precipitação em postos que não contém informações. Desta forma, foi considerado os valores de precipitações dos postos vizinhos e usados para preenchimento mensal e anual. Para isso, é necessário a utilização de pelo menos três postos vizinhos daqueles postos com falhas e que estejam localizados na mesma região climática. 
A Equação 1 apresenta o método de ponderação regional.

$$
P x=\frac{1}{3}\left(\frac{P z}{P z m}+\frac{P y}{P x m}+\frac{P w}{P w m}\right) \cdot P x m
$$

Onde $P x$ é o posto com a existência de lacunas a preencher e $P z, P y$ e $P w$ são os postos com dados disponíveis no mesmo intervalo de tempo, nos arredores do posto $P x$. Já as variáveis $P x m, P z m, P y m$ e $P w m$, são os valores médios da precipitação para cada posto. Dessa forma, foi possível corrigir as lacunas existentes e utilizar um número maior de postos pluviométricos no estudo.

\subsection{Procedimentos para definição dos anos-padrão e análise das séries históricas (1979-2017)}

Para a análise das chuvas optou-se inicialmente por estabelecer classes representativas do total das chuvas anuais para fins de individualizar os postos pluviométricos e os anos representativos do ritmo excepcional que se apresentam mais chuvosos ou mais secos em relação ao habitual na região. A metodologia utilizou o conceito de "anos-padrão" (MONTEIRO, 1973; 2015), tipificando os dados a partir da série histórica dos postos selecionados e, assim, estabelecendo classes que representam o padrão pluviométrico em escala temporal anual. Tal estratégia eminentemente geográfica é proposta e descrita por Monteiro (1991, p. 38) por representar os "diferentes graus de proximidade do ritmo 'habitual' ao lado daqueles afetados por irregularidades na circulação a modo de prever acidentes e impactos nas atividades humanas".

Pela técnica utilizada foi obtido o desvio absoluto a partir de uma proporção em relação à precipitação média, e estabelece categorias a partir dos valores dos desvios, podendo os agrupamentos ser avaliados qualitativamente para o padrão da precipitação do período e no processo de classificação dos anos extremos, a exemplo dos estudos elaborados por Silvestre et al. (2013) Buffon e Binda (2014) e Santos et al. (2017). O período adotado foi de 1979 a 2017 para cada posto, estabelecendo assim, os anos-padrão habituais e excepcionais pelo total médio anual de chuvas e seu respectivo desvio-padrão, conforme o modelo e os parâmetros estabelecidos na Figura 3.

\begin{tabular}{|c|c|c|}
\hline \multicolumn{3}{|c|}{ Metodologia Índice de Anos Padrões (IAP) } \\
\hline Classificação & Padrões Pluviométricos (SIGLAS) & Desvio (+) ou (-) \\
\hline Anos & Chuvoso (C) & $>+30 \%$ \\
\hline Chuvosos & Tendente a chuvoso (TC) & $+15 a+30 \%$ \\
\hline \multirow{3}{*}{$\begin{array}{r}\text { Anos } \\
\text { Normais }\end{array}$} & $\begin{array}{l}\text { Normal levemente tendente a chuvoso } \\
\text { (NTC) }\end{array}$ & $+5 a+15 \%$ \\
\hline & Normal (N) & 0 a $5 \%$ \\
\hline & $\begin{array}{l}\text { Normal levemente tendente a seco } \\
\text { (NTS) }\end{array}$ & $-5 a-15 \%$ \\
\hline \multirow{2}{*}{ Anos Secos } & Tendente a seco (TS) & $-15 a-30 \%$ \\
\hline & $\operatorname{Seco}(\mathrm{S})$ & $<-30 \%$ \\
\hline
\end{tabular}

Figura 3: Classificação da pluviosidade conforme a metodologia dos anos-padrão.

Nessa perspectiva, de acordo com Tavares (1976), os valores de precipitação que apresentarem desvios até $15 \%$ da média, são considerados anos habituais (Normais) e aqueles que mostrarem desvios positivos da ordem de $15-30 \%$ ou > 30\% em relação às médias, são considerados, respectivamente, Tendentes a Chuvoso e Chuvosos; enquanto que anos com desvios negativos de 15-30\% são definidos como Tendentes a Seco e com índices $<30 \%$ como anos secos. A utilização de anos-padrão foi feita em inúmeras pesquisas ao longo das últimas décadas no campo da Climatologia Geográfica (MONTEIRO, 2015) e, apesar de variações nas técnicas e critérios utilizados para estabelecer classes representativas (SILVESTRE et al., 2013; FONTÃO; ZAVATTINI, 2019), apresenta convergência conceitual e um objetivo em comum, por buscar o 
entendimento do padrão climático habitual e excecional de uma região ao longo de um determinado período de tempo.

Identificadas as classes representativas dos padrões pluviométricos, aplicou-se o método de interpolação dos dados por meio do inverso da distância para espacializar o número de ocorrências das classes. Trata-se de uma ferramenta de Sistema de Informação Geográfica (SIG) que pode estimar espacialmente um valor para um determinado local que não apresenta informações, por meio do cálculo da média ponderada das amostras vizinhas pelo inverso da distância entre o ponto a ser interpolado dentro de uma vizinhança (FARIAS et al., 2017). Na análise dos mapas, levou-se em conta também a influência da orografia da superfície regional nos padrões de precipitação (ROE, 2005; HOUZE, 2012). Por fim foram selecionados dois anos padrão representativos do ritmo excepcional, um chuvoso e outro seco na área de estudo para aprofundar a investigação da circulação atmosférica, e, efetivamente, identificar na gênese regional o efeito orográfico nas chuvas.

\subsection{Análise Rítmica dos anos seco e chuvoso}

A Análise Rítmica consiste numa tradicional técnica de pesquisa da Escola Brasileira de Climatologia Geográfica, inicialmente introduzida e amplamente descrita por Monteiro (1971; 1973; 1991; 2015). O procedimento em questão objetiva analisar a circulação atmosférica em nível minimamente diário no intuito de identificar os tipos de tempo (massas de ar ou frentes) que atuaram sobre uma determinada área e, ao examiná-los sequencialmente, identificar os encadeamentos e o ritmo climático da região, utilizando para tanto um gráfico contendo a dinâmica de diferentes variáveis climáticas, cartas sinóticas e imagens de satélite. Posto isto, foram coletados e utilizados dados diários e horários de todas as variáveis disponíveis na Estação Meteorológica SÃO CARLOS-SP, operada pelo Instituto Nacional de Meteorologia (INMET, 2020), além de cartas sinóticas elaboradas pela Marinha do Brasil (2020) e imagens de satélite disponibilizadas no Centro de Previsão de Tempo e Estudos Climático do Instituto Nacional de Pesquisas Espaciais (CPTEC/INPE, 2020) e pelo International Satellite Cloud Climatology Project do Global ISCCP B1 Browse System (KNAPP, 2008).

Dessa forma, para os dois anos-padrão selecionados na pesquisa, foram elaborados gráficos de Análise Rítmica contendo a sequência diária/horária das variáveis temperatura, precipitação, umidade, pressão, vento, nebulosidade e insolação, quadro que auxiliou na classificação empírica dos sistemas atmosféricos em dois horários diários: 9 horas (12 G.M.T.) e 21 horas (00 G.M.T.). Nesse caso, para sintetizar os resultados, transcreveram-se a dinâmica da temperatura, precipitação e os sistemas atmosféricos. Vale ressaltar que, apesar dos métodos manuais e empíricos de classificação dos tipos de tempo terem recebido questionamentos ao longo das últimas duas décadas, devido ao alto grau de subjetividade envolvido na atribuição das massas de ar e frentes (YARNAL et al., 2001; LEWIS e KEIM, 2015), tal metodologia permanece sendo utilizada em trabalhos recentes por aproximar os pesquisadores da compreensão do ritmo de sucessão dos tipos de tempo atmosféricos e, gerando assim, bons resultados, inclusive possibilitando uma relação e cooperação com métodos automáticos de classificação (FONTÃO et al, 2018). Por conseguinte, utilizou-se na pesquisa a proposta de classificação de massas de ar e frentes de Zavattini e Boin (2013), baseada nas publicações de Monteiro $(1971,1973)$ e nos avanços recentes da Climatologia Geográfica.

\section{Resultados e Discussões}

\subsection{Análise das chuvas anuais e escolha dos anos-padrão}

A Figura 4A sintetiza na forma de tabela os resultados obtidos a partir dos procedimentos detalhados anteriormente, evidenciando a distribuição das classes e a frequência dos 1209 dados pluviométricos anuais do universo de análise, compreendendo o período de 1979-2017 para os 31 postos selecionados. Os valores dos desvios foram estabelecidos qualitativamente em categorias: Normais - Normal Tendente a Chuvoso (NTC), Normal (N) e Normal Tendente a Seco (NTC); Chuvosas - Tendente a Chuvoso (TC) e Chuvoso (C); e Secas - Tendente a Seco (TC) e Seco (S). No caso, a escolha das nomenclaturas procurou retratar o padrão observado no ano em específico, tendo em vista a realidade climática da área de estudo.

Tendo em vista as sete classes definidas na investigação, elaborou-se o histograma de frequência dos dados que pode ser observado na Figura 4B. Nele, nota-se que a classe Normal foi a que apresentou maior frequência com 321 ocorrências, seguida da classe NTS com um total de 278 vezes. Por outro lado, as classes consideradas extremas, Seco e Chuvoso, apresentaram as menores frequências no gráfico, somando respectivamente 49 e 59 ocorrências no total, além de terem se concentrado em alguns anos específicos, com amplo destaque para 1983 (30 postos na classe Chuvoso) e 2014 (18 postos na classe Seco). Dentre as 1209 ocorrências anuais de chuva, as atribuídas como Normais (N, NTC e NTS) apresentaram uma frequência de 
$66,2 \%$ em relação ao total, enquanto as classes Chuvosas 16,2\% e Secas $17,6 \%$ correspondem juntas a $33,8 \%$ dos dados, levando em conta toda a variabilidade interanual e a média de chuvas no período que foi de 1481,1 milímetros.

(A)

\begin{tabular}{|c|c|c|c|}
\hline Classificação & Desvio (mm) & Total & $\%$ \\
\hline C & $>444,4$ & 59 & 4,8 \\
\hline TC & 222,2 a 444,3 & 137 & 11,3 \\
\hline NTC & 74,1 a 222,1 & 201 & 16,6 \\
\hline N & $(-) 74$ a $(+) 74$ & 321 & 26,6 \\
\hline NTS & 73,9 a 222,1 & 278 & 22,9 \\
\hline TS & 222,2 a 444,3 & 164 & 13,5 \\
\hline S & $<444,4$ & 49 & 4 \\
\hline \multicolumn{4}{|c|}{ Total } \\
\hline
\end{tabular}

(B)

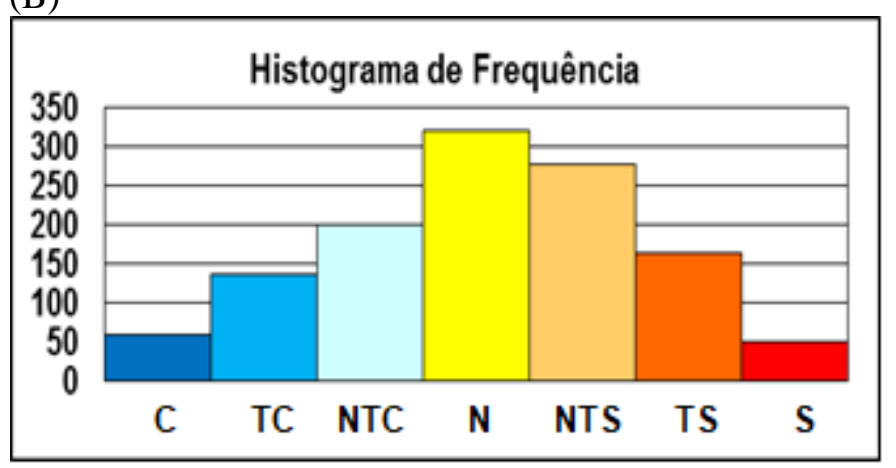

Figura 4: Distribuição total do número de frequência entre as classes (A); e, Histograma de frequência das classes (B)

Entre as classes tendentes, a TS com 13,5\% obteve uma porcentagem ligeiramente superior a TC com $11,3 \%$. No caso das classes extremas, a classe C ficou com $4,8 \%$ e a S com $4 \%$ dos dados, destacando-se nesse conjunto de dados o ano de 1983 como o mais chuvoso e o ano de 2014 como o mais seco de toda a série.

No intuito de visualizar a distribuição espacial dos dados por classes de frequência, a Figura 5 apresenta a distribuição das ocorrências para cada uma das sete classes adotadas neste estudo, considerando os 31 postos pluviométricos utilizados. Nela, podem-se observar em cada um dos mapas os locais onde as classes se concentraram. Por exemplo, na classe Normal $(\mathrm{N})$, o número de ocorrência variou de 6 a 15 vezes na área de estudo, sendo que na porção centro-sul do mapa os postos P29, P30, P31, P7, P15 e P14, localizados nos arredores das Serras de São Pedro e Itaqueri, foram os que apresentaram maior frequência, além das áreas de fundo de vale como os postos P16 e P27. Já nas áreas da Depressão Periférica Paulista, localizadas a leste do mapa, os postos P4, P1, P21 foram as que apresentaram menor ocorrência, somado a outras áreas à noroeste da área de estudo.

No caso das classes extremas, a frequência mostrou-se restrita ao intervalo de 0 a 4 vezes para a classe C e de 0 a 7 vezes para a classe $S$, a depender do posto pluviométrico. No caso do mapa de classe Chuvoso (C), é possível observar uma faixa representando um número maior de ocorrências nas áreas onde se encontram as serras inseridas ao norte e sul da região, destacando-se em relação às áreas periféricas a leste e oeste do mapa que possuem menor altitude. Na classe Seco (S), as áreas situadas em setores mais rebaixados do relevo, sobretudo em domínios da Depressão Periférica Paulista, apresentaram um número maior de postos pluviométricos com anos-padrão secos, contrastando com a região serrana situada à sudoeste da área de estudo, que apresentou baixa ou nenhuma frequência de anos secos. 


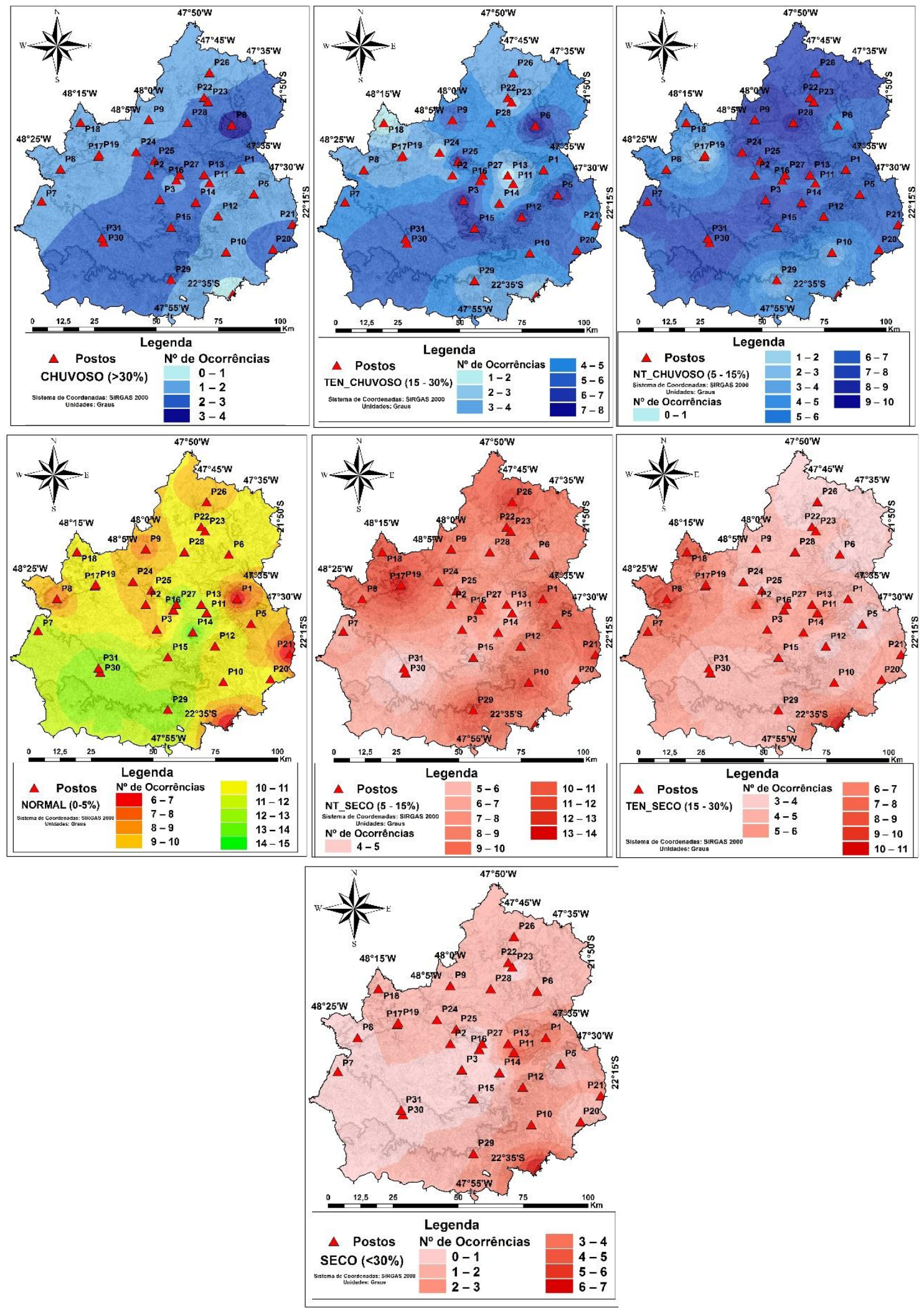

Figura 5: Mapas das sete classes pluviométricas espacializadas.

Diante disso, é possível notar que áreas mais rebaixadas do relevo situadas à sul-sudeste na Depressão Periférica Paulista, à noroeste na vertente poente do Planalto Ocidental Paulista e nos vales localizados em áreas mais centrais da área de estudo não contam com o input hídrico proporcionado pelas chuvas orográficas devido as condições altimétricas, apresentando um número maior de ocorrências em classes com desvios negativos em relação à média. Por outro lado, nos postos pluviométricos localizados nas serras e cuestas que formam um eixo mais central no sentido sudoeste-nordeste, notou-se um volume maior de chuvas anuais em relação aos demais postos e uma maior frequência de anos-padrão chuvosos, indicando influência do efeito orográfico destas morfoestruturas nas precipitações. 
Os resultados obtidos até o momento aproximam-se dos observados por Santos et al. (2018), que verificaram uma relativa influência do efeito orográfico nos valores máximos de índices climáticos de chuvas na região centro-leste do estado de São Paulo, sobretudo nos totais máximos de intensidade das chuvas no reverso das Cuestas Basálticas nas regiões Norte (serra de São Carlos) e Sul (serra de Itaqueri). Nesse sentido, enfatiza-se que a influência orográfica desempenha um papel fundamental na interação entre a atmosfera e o restante do sistema terrestre, interferindo nos padrões de precipitação em uma ampla variedade de escalas de tempo (ROE, 2005). Assim, buscando aprofundar a análise em uma escala temporal de detalhe, na etapa seguinte foram selecionados para prosseguir na investigação os dois anos mais extremos observados em toda a série histórica: 1983 (ano-padrão chuvoso) e 2014 (ano-padrão seco).

\subsection{Análise Rítmica dos anos-padrão excepcionais (chuvoso e seco)}

O procedimento de pesquisa para identificação de sistemas atmosféricos foi aplicado aos anos-padrão de 1983 e 2014, chuvoso e seco, respectivamente. Nesta etapa do estudo, as cartas sinóticas e imagens de satélite utilizadas permitiram que os índices pluviométricos fossem analisados visando a identificação da dinâmica dos sistemas atmosféricos e possível gênese dos eventos extremos responsáveis pela pluviosidade dos referidos anos. As Figuras 6 e 7 transcrevem os resultados da Análise Rítmica, associando a frequência diária dos diferentes tipos de sistemas frontais e massas de ar que atuaram na região às variáveis temperatura e precipitação nos dois anos selecionados.

O ano de 1983 apresentou um verão intensamente chuvoso, associado a uma participação vigorosa de sistemas frontais sobre a região e a persistentes avanços de correntes de sul que em diversos episódios estacionaram na área e ocasionaram fortes episódios de chuva. Apesar de não apresentar alturas diárias superiores a 70 milímetros, a frequência elevada e constante de dias chuvosos mostrou-se excepcional para a área, sobretudo associados à frente estacionária como, por exemplo, entre os dias 12 e 20 de janeiro. Ademais, mesmo com 42 dias seguidos sem chuva (entre julho e agosto), a estiagem de outono e inverno mostrou-se consideravelmente fraca e descontinuada por episódios considerados pouco frequentes nesta época, como observado entre 28 de maio e 4 de junho, período em que os sistemas frontais perduraram por vários dias na área e repercutiram em precipitações intensas na região. A retomada antecipada do ritmo pluvial mais intenso logo em setembro contribuiu ainda mais para a excepcionalidade desse ano, que contou ainda com precipitações intensas em dezembro e destacou-se pela elevada pluviosidade anual (registrando valores superiores a 2 mil milímetros em toda a área de estudo).

Em relação a 2014, observa-se que o ano se inicia sob uma expressiva participação de massas de ar tropicais, sobretudo mTA e mTC, sucedendo-se de maneira alternada e resultando em poucos dias chuvosos e reduzidos volumes de precipitação, na maior parte das vezes associadas às linhas de instabilidade tropicais. Fluxos de origem austral só passariam a ocorrer a partir de meados de fevereiro, no entanto, sem resultar em chuvas significativas e, após rompida a inércia, somente no mês de março as passagens frontais voltariam a atingir a região intertropical e repercutir em algumas chuvas consideráveis, porém insuficientes se considerarmos o ritmo habitual da estação na região central do estado de São Paulo. Ao longo do outono e inverno, as precipitações permaneceram acanhadas e pouco frequentes na região, sobressaindo-se nessa época um único episódio expressivo entre 22 e 23 de maio, com chuvas geneticamente associadas a tipos de tempo frontais, no entanto, a estiagem prolongou por vários meses ao longo do ano, e, mesmo atenuada por alguns episódios pluviais em setembro, perdurou até o final do mês de outubro. Somente a partir dos meses de novembro e dezembro, a atuação mais intensa dos sistemas frontais começaria a produzir chuvas mais volumosas e próximas ao habitual da região investigada, amenizando ligeiramente o quadro pluvial excepcionalmente seco deste ano.

De maneira comparativa e sintetizando os resultados das análises para os anos de 1983 e 2014, pode-se mencionar que o ano úmido apresentou um verão associado a sucessivas passagens frontais, que se sobressaíram por permanecerem por vários dias sobre a região e resultarem em tipos de tempo frontais úmidos, essencialmente nublados e/ou encobertos e com chuvas abundantes e frequentes com volumes e características excepcionais para a área de estudo. 


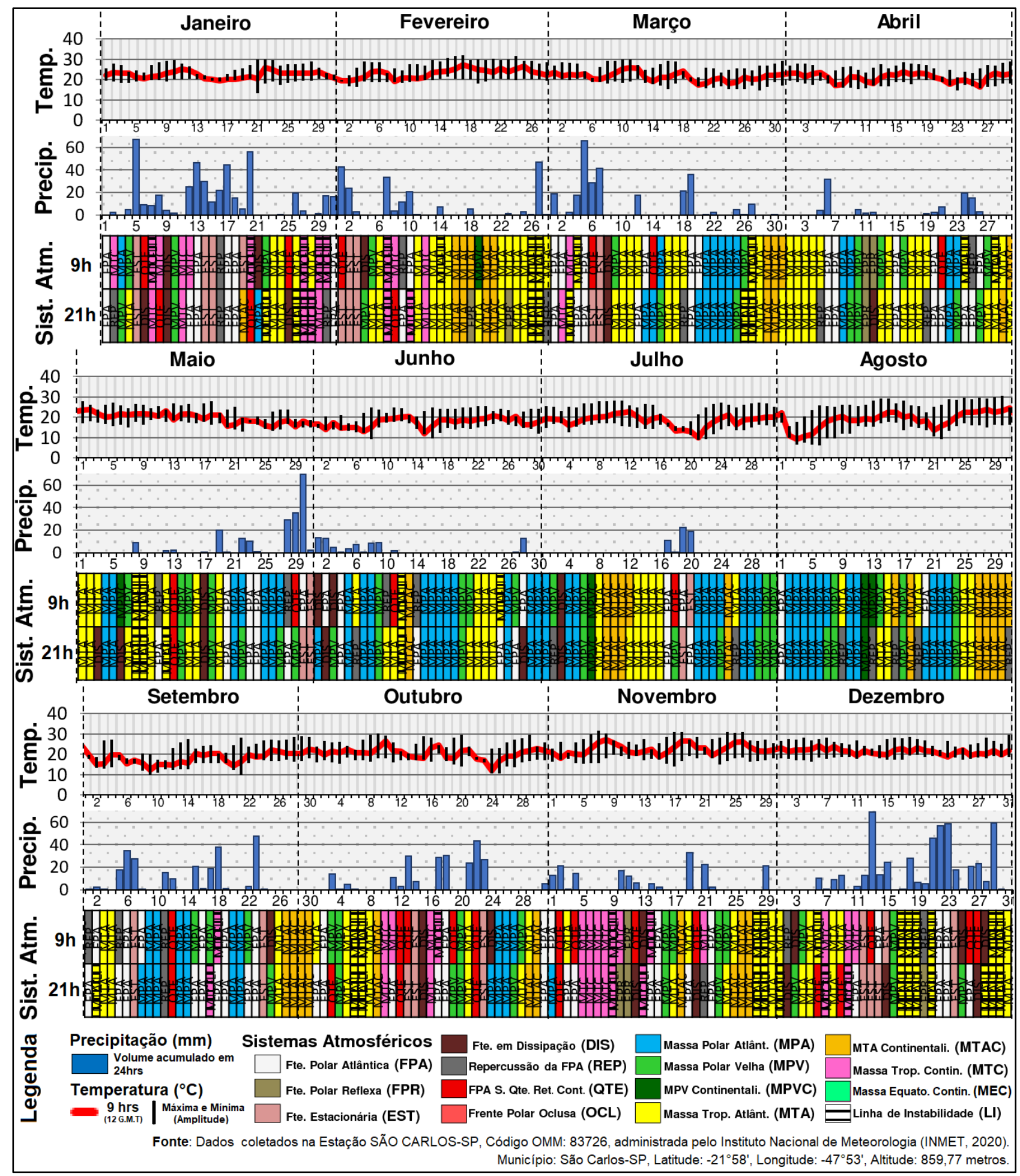

Figura 6: Análise Rítmica dos sistemas atmosféricos para o ano de 1983.

Por outro lado, no ano seco, a intensa presença de massas de ar tropicais em janeiro e fevereiro repercutiu em tipos de tempo estáveis e longas sequências de dias secos, pouco frequentes nessa época do ano. Tal conjuntura resultou da atuação persistente de anticiclones que dificultaram o avanço das frentes na região.

Ademais, o ritmo de sucessão dos tipos de tempo manteve-se bastante distinto entre os dois anos-padrão até o final de outubro, cuja estiagem em 2014 mostrou-se intensa enquanto 1983 apresentou sucessivos avanços frontais e episódios pluviais intensos mesmo em meses habitualmente pouco chuvosos. Apesar do ritmo de alternância entre sistemas polares e sistemas tropicais, quase sempre regulados pelos avanços da Frente Polar Atlântica e suas inflexões ter mostrado certas semelhanças nos meses de novembro e dezembro em 1983 e 2014, no ano chuvoso apresentou maior intensidade pluvial como atesta o volume registrado nos pontos de coleta. 


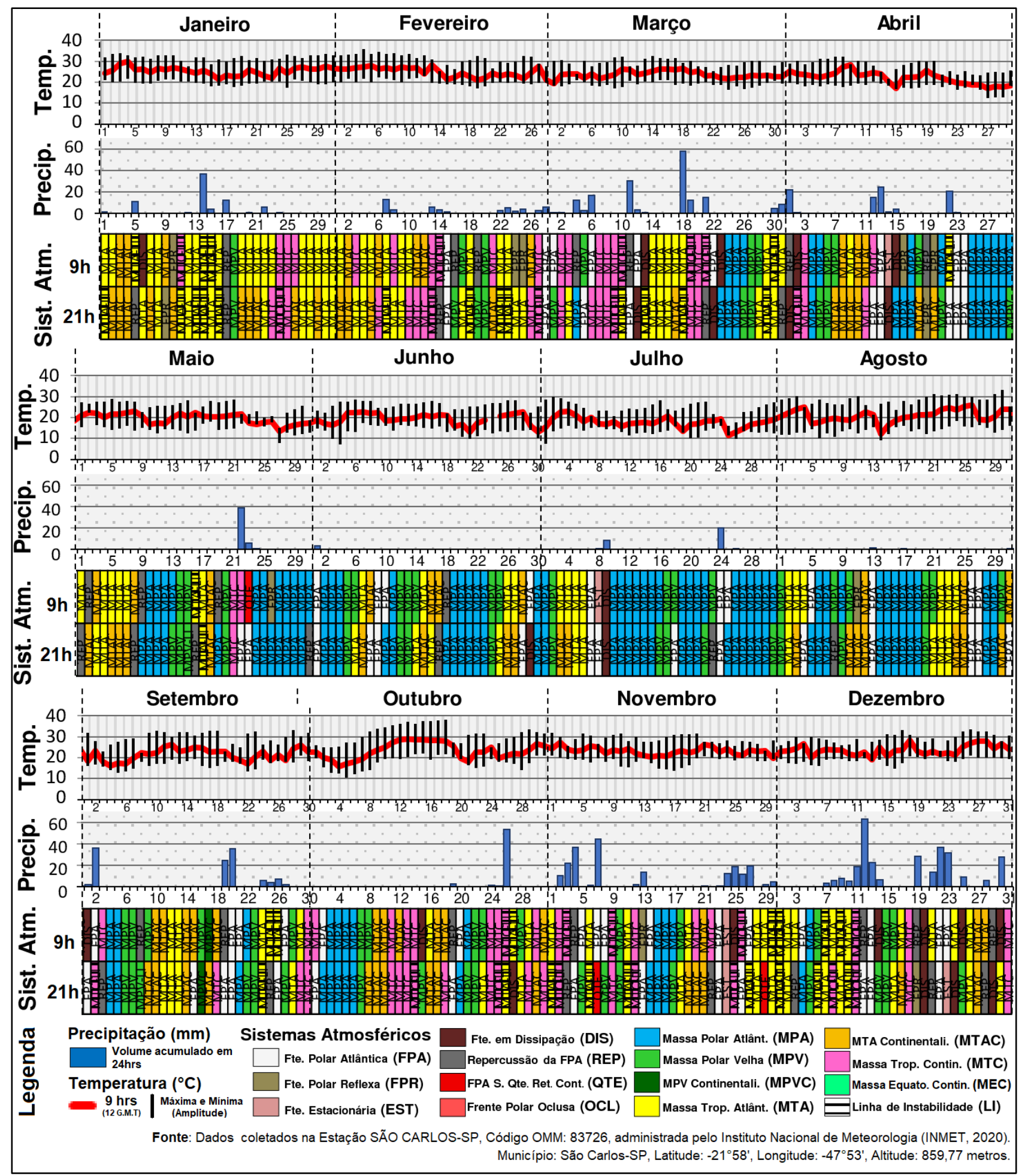

Figura 7: Análise Rítmica dos sistemas atmosféricos para o ano de 2014.

Em vista disso, a precipitação anual de 1983 manteve-se superior à de 2014 em todos os 31 postos pluviométricos utilizados neste estudo, chegando, em alguns casos a ultrapassar o dobro da altura de chuva em milímetros. A Figura 8 exibe um gráfico contendo o total da precipitação (PRCPTOT) registrada em cada posto pluviométrico ao longo do ano de 1983 variando de 1772 a $3036 \mathrm{~mm}$, situando-se em todos superior à média histórica de 1481,1 mm. No ano 2014 os registros variaram entre 440 e $1297 \mathrm{~mm}$, contendo valores significativamente abaixo da média supracitada em todos os pontos de coleta, com destaque para os postos $\mathrm{P} 25, \mathrm{P} 27, \mathrm{P} 30$ e P31 que registraram os maiores acumulados pluviométricos. Ao longo dos 38 anos (1979-2017) de registros, o menor valor anual acumulado de precipitação foi de 440,8 mm e o maior de 3038 $\mathrm{mm}$, demonstrando a elevada amplitude anual de 2597,2 $\mathrm{mm}$ que se observa na área de estudo. 


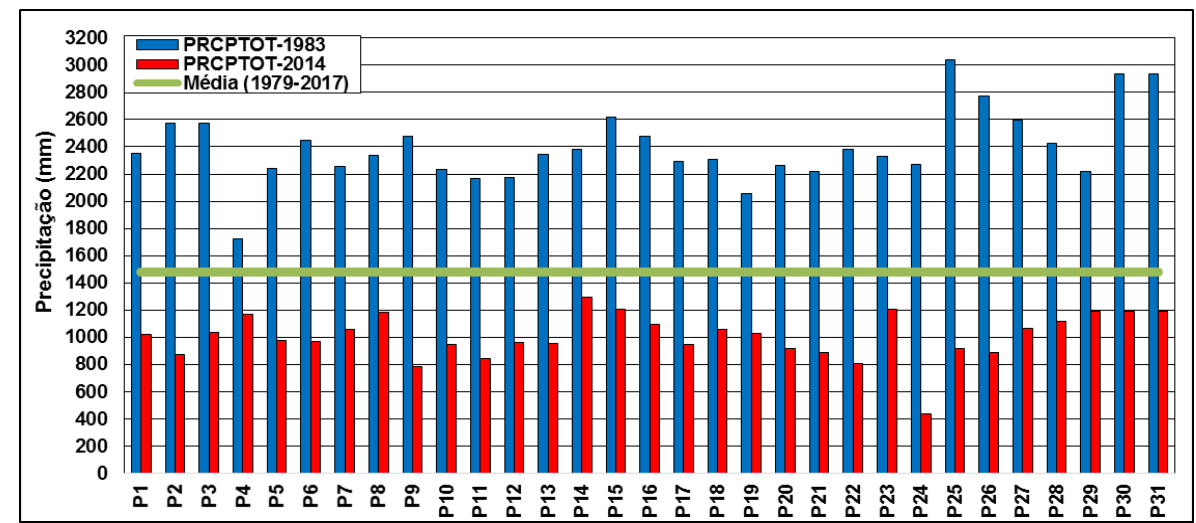

Figura 8: Gráfico de Precipitação Total Anual para todos os postos no ano de 1983 e 2014.

Diante dos volumes de chuva que afetaram de maneira desigual a área de estudo nos dois anos-padrão, optou-se por verificar a distribuição espacial do fenômeno pluvial na região. A Figura 9 apresenta o total anual das chuvas interpoladas na região, tanto para 1983 como 2014.
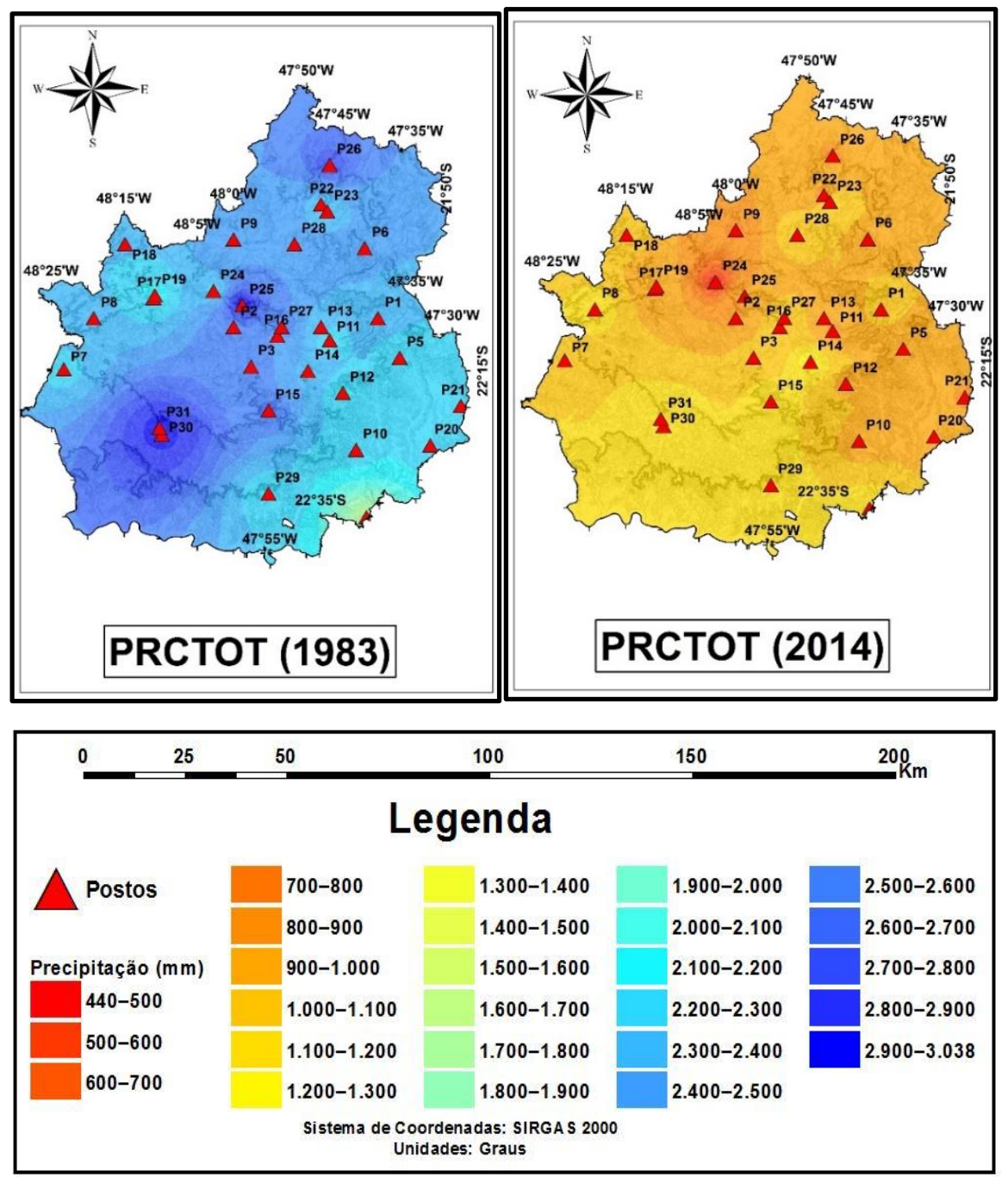

Figura 9: Mapas do total anual da precipitação do ano de 1983 e 2014.

Nota-se que na porção centro-sul do mapa, setor onde localiza-se a Serra de Itaqueri e o vale do Lobo, ocorreram índices pluviométricos extremamente elevados para o ano de 1983 (P2, P3, P15, P16, P25, P27, P30 e P31) e ligeiramente superiores em relação às outras áreas no ano de 2014 (P14, P15, P29, P30 e P31), fator também observado com menor magnitude em pequenas porções no setor norte da área (P22, P23, P26 e P28). Porém, nas áreas de menor altitude à sudeste e noroeste da região (P4, P9, P10, P12, P17, P19, P20, 
P21 e P24), respectivamente sob domínio morfológico da Depressão Periférica Paulista e da vertente oeste do Planalto Ocidental Paulista, as chuvas mostraram-se reduzidas em ambos os mapas.

Desta maneira, observando-se os dois mapas da figura, é possível verificar que nas regiões onde a declividade e altitude são elevadas, os índices pluviométricos manifestam-se mais elevados em relação ao que se registra nas demais porções da área estudada. Em face disto, por tratar-se de dois anos representativos para a série histórica que se situam nos seus extremos opostos, entende-se que a maior pluviosidade destas regiões em relação às demais tanto em 1983 como em 2014 indica possivelmente a influência do processo orográfico na formação de chuvas e nos volumes precipitados. Em razão disto, apesar dos valores anuais totais não descreverem o comportamento da precipitação ao longo dos doze meses ou pelos trezentos e sessenta e cinco/seis dias da translação terrestre ao redor do sol, e, a análise rítmica ter sido elaborada de maneira regional, é possível inferir com base nos resultados obtidos e nas obras de Smith e Bastard (2004), Roe (2005), Ebtehaj e Foufoula-Georgiou (2010) e Houze (2012), entre outros, que a região possivelmente sofre uma considerável influência do efeito orográfico no setor de domínio das serras e cuestas.

\section{Considerações finais}

O estudo em questão tornou possível identificar classes representativas do padrão habitual e extremo das chuvas na porção central do Estado de São Paulo, avaliando assim a frequência das precipitações anuais na região e, especificamente, nos dois anos excepcionais identificados na série histórica: 1983 (chuvoso) e 2014 (seco). Nesse caso, a circulação atmosférica foi nitidamente distinta em ambos os períodos, sobretudo durante o primeiro semestre, refletindo numa dinâmica hidroclimática discrepante e denotando um processo que resultou em chuvas intensas no verão do ano chuvoso e numa acentuada (e prolongada) estiagem no ano seco, fenômenos que seguramente afetaram a população residente da área de estudo.

Do mesmo modo, a análise espacial dos dados contidos na série histórica permitiu identificar como as características da paisagem influenciam o desempenho da precipitação, mesmo nos momentos em que as forças hegemônicas da circulação atmosférica atuam de maneira diferenciada ao longo de um período. Nesse aspecto, verificou-se que a orografia apresentou uma significativa influência nas precipitações, com destaque para chuvas mais intensas em morfoestruturas de serras e cuestas existentes na região, fator que possivelmente continuará influindo na distribuição e intensidade das chuvas sobre a área investigada, não obstante à conjuntura atmosférica.

Dessa forma, os resultados contribuíram para o entendimento do comportamento das precipitações na região em escala temporal e espacial, permitindo, por conseguinte, que estudos e ações possam ser desdobrados no aprofundamento desse conhecimento e na capacidade de gerenciamento das diferentes conjunturas. A metodologia aplicada produziu respostas significativas, todavia limitou-se a um número pequeno de postos pluviométricos e a apenas dois anos-padrão extremos, tornando necessário novas investigações em nível de detalhe e com novas técnicas para aprofundar na compreensão do tema investigado, e, assim, produzir resultados ainda mais específicos e que suscitem interpretações detalhadas da influência orográfica regional nas precipitações e subsídios para o planejamento e a gestão dos municípios no tocante à situações de eventos extremos.

Por fim, diante dos dados analisados e dos materiais produzidos, espera-se que os produtos deste artigo possam contribuir para o planejamento desenvolvido na porção central do Estado de São Paulo, assim como para futuras pesquisas que seguramente serão realizadas para aprimorar e asseverar as conclusões obtidas e aqui descritas, pois, dada a dependência que a sociedade contemporânea possui dos recursos hídricos, cumpre que o conhecimento acerca do input - precipitações - seja continuamente perseguido e estimulado, pois a magnitude dos problemas advindos das secas e enchentes não permite que a questão do abastecimento e drenagem seja administrada pelo improviso.

\section{Referências}

ABREU, F.G.; SOBRINHA, L.A.; BRANDÃO, J.L.B. Análise da distribuição temporal das chuvas em eventos hidrológicos extremos. Engenharia Sanitária e Ambiental, v. 22, n. 2, p. 239-250, 2017. http://dx.doi.org/10.1590/s1413-41522016146750

AGUILAR, R.L.; CUNHA, C.M.L. Análise morfoestrutural de um setor da Serra da Atalaia, Analândia/Corumbataí (SP). Revista Brasileira de Geografia Física, v. 8, n. 05, p. 1410-1434, 2015. https://doi.org/10.26848/rbgf.v8.5.p1410-1434

BARRY, G.R.; CHORLEY, J.R. Atmosfera, tempo e clima. 9. ed. Porto Alegre: Ed. Bookman, 2013. 
BERTONI, J.C.; TUCCI, C.E.M. Precipitação. In: TUCCI, C.E.M. (Org.). Hidrologia: ciência e aplicação. 4 ed. Porto Alegre: Editora da UFRGS/ABRH, 2009. p. 177-241.

BUFFON, E.M.; BINDA, A.L. Variabilidade no regime pluvial do município de Abelardo Luz (SC) no período de 1958 a 2008: interações entre mecanismos de teleconexão decadal e interanual. Revista Brasileira de Climatologia, v. 13, 2014. http://dx.doi.org/10.5380/abclima.v13i0.33598

CORVALÁN, S.B.; GARCIA, G.J. Avaliação ambiental da APA Corumbataí segundo critérios de erodibilidade do solo e cobertura vegetal. Geociências, v. 30, n. 2, p. 269-283, 2011.

CPTEC/INPE. Centro de Previsão de Tempo e Estudos Climáticos. Disponível em: <http://www.cptec.inpe.br/>. Acesso em: 13 jan. 2020.

DONAT, M.G.; LOWRY, A.L.; ALEXANDER, L.V.; O'GORMAN, P.A.; MAHER, N. More extreme precipitation in the world's dry and wet regions. Nature Climate Change, v. 6, n. 5, p. 508-513, 2016. https://doi.org/10.1038/NCLIMATE2941

EASTERLING, D.R; EVAND, J.L.; GROISMAN, P.Y.; KARL, T.R.; KUNKEL, K.E.; AMBENJE, P. Observed variability and trends in extreme climate events: a brief review. Bulletin of the American Meteorological Society, v. 81, n. 3, p. 417-426, 2000. https://doi.org/10.1175/15200477(2000)081\%3C0417:OVATIE\%3E2.3.CO;2

EBTEHAJ, M.; FOUFOULA-GEORGIOU, E. Orographic signature on multiscale statistics of extreme rainfall: A storm-scale study. Journal of Geophysical Research: Atmospheres, v. 115, n. D23, 2010. https://doi.org/10.1029/2010JD014093

FARIAS, O.G.; FRANCISCO, C.N.; SENNA, M.C.A. Avaliação de métodos de interpolação espacial aplicados à pluviosidade em região montanhosa no litoral sul do estado do Rio de Janeiro. Revista Brasileira de Climatologia, v. 21, p.172-185, 2017. http://dx.doi.org/10.5380/abclima.v21i0.52065

FONTÃO, P.A.B.; ZAVATTINI, J.A.; SHERIDAN, S.C.; ARMOND, N.B. Gênese das chuvas em São Paulo (SP): estudo comparativo entre a 'Spatial Synoptic Classification' e a 'Análise Rítmica em Climatologia'. Revista Brasileira de Climatologia, v. 23, p. 267-288, 2018. http://dx.doi.org/10.5380/abclima.v23i0.58657

FONTÃO, P.A.B.; ZAVATTINI, J.A. Variabilidade das chuvas anuais na Região Metropolitana de São Paulo (RMSP) e no Sistema Cantareira: classificação e frequência dos anos-padrão. Revista Brasileira de Geografia Física, v. 12, n. 2, p. 457-469, 2019. https://doi.org/10.26848/rbgf.v12.2.p457-469

GENOVEZ, A.M.; ZUFFO, A.C. Chuvas intensas no Estado de São Paulo: Estudos existentes e análise comparativa. Revista Brasileira de Recursos Hídricos, v. 5, n. 3, p. 45-58, 2000. https://doi.org/10.21168/rbrh.v5n3.p45-58

GONÇALVES, V. F. M.; MANZIONE, R. L.: Estimativa da recarga das águas subterrâneas no sistema aquífero Bauru (SAB). Geo UERJ, Rio de Janeiro, n. 35, e37063, 2019. https://doi.org/10.12957/geouerj.2019.37063

HOUZE, R. A. Orographic effects on precipitating clouds. Reviews Geophysics, 50, RG1001, 2012. https://doi.org/10.1029/2011RG000365

INMET. Instituto Nacional de Meteorologia. Disponível em: <http://www.inmet.gov.br/>. Acesso em: 06 jan. 2020.

KNAPP, K.R. Scientific data stewardship of International Satellite Cloud Climatology Project B1 global geostationary observations. Journal of Applied Remote Sensing, v. 2, n. 1, p. 023548, 2008. https://doi.org/10.1117/1.3043461 
LEWIS, A.B.; KEIM, B.D. History and Applications of Manual Synoptic Classification. Reference Module in Earth Systems and Environmental Sciences, 2015. https://doi.org/10.1016/B978-0-12-409548-9.09521$\mathrm{X}$

MAIA, D.C.; FONTÃO, P.A.B.; SOUZA, L.B.; CHRISTOFOLETTI, A.L.H.; AZEVEDO, T.S. Hail rain and its geographical repercussions in the countryside of São Paulo (SP) state. Mercator, Fortaleza, v. 18, 2019. https://doi.org/10.4215/rm2019.e18006

MARINHA DO BRASIL. Marinha do Brasil. Disponível em: <https://www.marinha.mil.br/>. Acesso em: 14 jan. 2020.

MARVEL, K.; BIASUTTI, M.; BONFILS, C.; TAYLOR, K.E.; KUSHNIR, Y.; COOK, B.I. Observed and projected changes to the precipitation annual cycle. Journal of Climate, v. 30, n. 13, p. 4983-4995, 2017. https://doi.org/10.1175/JCLI-D-16-0572.1

MONTEIRO, C.A.F. A análise rítmica em climatologia: problemas da atualidade climática em São Paulo e achegas para um programa de trabalho. Climatologia, n. 01, p. 01-21, 1971.

MONTEIRO, C.A.F. A Dinâmica Climática e as Chuvas no Estado de São Paulo: estudo geográfico sob a forma de atlas. São Paulo: USP/IG, 1973.

MONTEIRO, C.A.F. Clima e Excepcionalismo: conjecturas sobre o desempenho da atmosfera como fenômeno geográfico. Florianópolis: UFSC, 1991.

MONTEIRO, C.A.F. (Org.). A construção da Climatologia Geográfica no Brasil. $1^{\text {a }}$ Edição. Campinas, SP: Editora Alínea, 2015.

MORUZZI, R.B.; OLIVEIRA, S.C. Relação entre intensidade, duração e freqüência de chuvas em Rio Claro, SP: métodos e aplicação. Teoria e Prática na Engenharia Civil, n. 13, p. 59-68, 2009.

NEVES, G. Z. F.; GALLARDO, N. P.; VECCHIA, F. A. S. A Short Critical History on the Development of Meteorology and Climatology. Climate, v. 5, p. 23, 2017. https://doi.org/10.3390/cli5010023

ROSS, J.L.S.; MOROZ, I.C. Mapa geomorfológico do estado de São Paulo. Revista do Departamento de Geografia, v. 10, p. 41-58, 1996. https://doi.org/10.7154/RDG.1996.0010.0004

PENTEADO, M.M. Geomorfologia do Setor Centro-Ocidental da Depressão Periférica Paulista (Tese de Doutorado). São Paulo: Instituto de Geografia-USP, 1976.

PEREIRA, D.N.B.; SANTOS, B.C.; SILVA, M.S.D.; PERUSSI, R.; HORTA, I.T.L.G; SANCHES, R. G.; ANTONUCCI, B.; KAYANO, T.Y.K.; BRUSSOLO, R.G.; NEVES, G.Z.F. Caracterização de vazões do ribeirão do lobo em brotas (sp). In: XXIII Simpósio Brasileiro de Recursos Hídricos, 2019, Foz do IguaçuPR, 2019.

PFAHL, S.; O'GORMAN, P.A.; FISCHER, E.M. Understanding the regional pattern of projected future changes in extreme precipitation. Nature Climate Change, v. 7, n. 6, p. 423-427, 2017. https://doi.org/10.1038/NCLIMATE3287

PINHEIRO, M.R.; QUEIROZ NETO, J.P. Reflexões sobre a gênese da Serra Geral e da Depressão Periférica Paulista: O exemplo da região da Serra de São Pedro e do Baixo Piracicaba, SP. Revista do Instituto Geológico, v. 35, n. 1, p. 47-59, 2014. http://dx.doi.org/10.5935/0100-929X.20140004

RIBEIRO, A.G. Climatologia geográfica e a organização do espaço agrário. Boletim de Geografia Teorética. Rio Claro, v. 23, n. 45-46, p. 34-38, 1993.

ROE, G.H. Orographic precipitation. Annual Review of Earth and Planetary Sciences, v. 33, p. 645-671, 2005. https://doi.org/10.1146/annurev.earth.33.092203.122541 
SANCHES, R.G.; NEVER, G.Z.F.; SANTOS, B.C.; SILVA, M.S.D.; PEREIRA, D.N.B.; TECH, A.R.B. Intense Rainfall in São Carlos/SP: Determination of Threshold Values Using Climate Indices and Their Spatio-Temporal Repercussion. American Journal of Climate Change, v. 7, n. 3, p. 388, 2018. https://doi.org/10.4236/ajcc.2018.73023

SANTOS, B.C.; SOUZA, P.H.; VECCHIA, F.A.S. A caracterização da precipitação do ano hidrológico de 2013-2014 na região de São Carlos/SC e sua repercussão no espaço geográfico. Revista Brasileira de Climatologia, v. 21, 2017. http://dx.doi.org/10.5380/abclima.v21i0.51505

SANTOS, B.C.; SANCHES, R.G.; SILVA, M.S.D.; KAYANO, T.Y.K.; SOUZA, P.H.; TECH, A.R.B. Análise do efeito orográfico por meio da interpolação de índices climáticos. Revista de Geografia-PPGEOUFJF, v. 8, n. 2, p. 114-132, 2018. https://doi.org/10.34019/2236-837X.2018.v8.26005

SETH, A.; FERNANDES, K.; CAMARGO, S.J. Two summers of São Paulo drought: Origins in the western tropical Pacific. Geophysical Research Letters, v. 42, n. 24, p. 10,816-10,823, 2015. https://doi.org/10.1002/2015GL066314

SILVESTRE, M.R.; SANT'ANNA NETO, J.L.; FLORES, E.F. Critérios estatísticos para definir anos padrão: uma contribuição à climatologia geográfica. Revista Formação, v. 2, n. 20, 2013. https://doi.org/10.33081/formacao.v2i20.2360

SMITH, R.B.; BARSTAD, I. A linear theory of orographic precipitation. Journal of the Atmospheric Sciences, v. $61, \quad$ n. 12 , p. 1377-1391, 2004. https://doi.org/10.1175/15200469(2004)061\%3C1377:ALTOOP\%3E2.0.CO;2

TAVARES, A.C. Critérios de escolha de anos padrões para análise rítmica. Geografia, v. 1, n. 1, p. 79-87, 1976.

TAVARES, A.C.; REYNALDO, N.A.; DONATTO, M.C.B.D.C.; CRUZ, M. P. O Uso da Análise Episódica na Caracterização de Aspectos Topoclimáticos da Serra de Itaqueri-SP. Boletim de Geografia - UEM, v. 3 , n. 3, p. 84-108, 1985.

YARNAL, B.; COMRIE, A.C.; FRAKES, B.; BROWN, D.P. Developments and prospects in synoptic climatology. International Journal of Climatology, v. 21, n. 15, p. 1923-1950, 2001. https://doi.org/10.1002/joc.675

ZAVATTINI, J.A; BOIN, M.N. Climatologia Geográfica: teoria e prática de pesquisa. Campinas-SP: Editora Alínea, 2013.

(1) (웅 (2)

Este artigo é distribuído nos termos e condições do Creative Commons Attributions/AtribuiçãoNãoComercial-CompartilhaIgual (CC BY-NC-SA). 